\title{
Role of Transversus Abdominis Plane (TAP) Block in Day Case Laparoscopic Cholecystectomy (DCLC) - A Prospective Study
}

S.Gupta ${ }^{1 *}$, Arya $\mathrm{S}^{2}$, El-Medani $\mathrm{F}^{2}$, Walker $\mathrm{T}^{3}$

\author{
Brief Discussion
}

${ }^{1}$ Consultant Surgeon, Department of Surgery, Lister Hospital, Stevenage, UK.

${ }^{2}$ Registrar Surgery, Department of Surgery, Lister Hospital, Stevenage, UK.

${ }^{3}$ Consultant Anaesthetist, Department of Anaesthesia, Lister Hospital, Stevenage, UK..

\begin{abstract}
Background: Despite being accepted as a standard day case procedure, day case rates for laparoscopic cholecystectomy (LC) remain low. Post-operative pain, nausea and vomiting continue to be important obstacles to early discharge. Present study was undertaken to assess the role of transversus abdominis plane (TAP) block as an analgesic adjunct in improving procedure related outcomes for patients undergoing day case laparoscopic cholecystectomy (DCLC).

Methods: Patients undergoing day case DCLC were prospectively randomised to TAP and no TAP block groups after informed consenting. Patients in both the groups also received port site infiltration with Marcaine. Primary outcome measure was post-operative pain. Secondary outcome measures included post-operative nausea/vomiting scores, sedation scores, length of post-operative hospital stay, complication rates, re-admission rates and overall patient satisfaction scores.

Results: A total of 53 patients undergoing DCLC were randomised into TAP block (26) and no TAP block (27) groups. Both the groups were well matched for age, sex, ASA (American society of anaesthesiologists) grade and BMI (Body mass index). No significant differences were noted in the post-operative pain scores when measured at $2 \mathrm{~h}(\mathrm{p}-0.810), 4 \mathrm{~h}(\mathrm{p}-0.993)$, at discharge ( $\mathrm{p}-0.539)$ and first post-operative day ( $\mathrm{p}-0.491)$. Average post-operative hospital stay was 5.86h (4-8h) in the TAP group and $6.38 \mathrm{~h}(5-22 \mathrm{~h})$ in the no TAP group ( $\mathrm{p}-0.482)$. Post-operative nausea and sedation scores assessed at similar intervals did not reveal any significant difference between the two groups. Complication rates ( 3 patients in each group) and re-admission rates (none in each group) were similar for both the groups. Overall 42 patients (21 in each group) described the experience as highly satisfying with 9 patients reporting as satisfying (TAP-5, No TAP-4).

Conclusion: The study failed to prove any benefit from TAP block in patients undergoing elective DCLC.
\end{abstract}

Keywords: Laparoscopic Cholecystectomy; Day Case Laparoscopic Cholecystectomy; Transversus Abdominis Plane Block; TAP Block.

\section{*Corresponding Author:}

S.Gupta FRCS, FACS,

Consultant General Surgeon, Lister Hospital, Coreys Mill Lane, Stevenage, Herts, SG1 4AB, UK.

Tel: 00447958303566

Fax: 00441438285177

E-Mail: sanjay.gupta@nhs.net

Received: March 17, 2015

Accepted: April 09, 2015

Published: April 13, 2015

Citation: S.Gupta, Arya S, El-Medani F, Walker T (2015) Role of Transversus Abdominis Plane (TAP) Block in Day Case Laparoscopic Cholecystectomy (DCLC) - A Prospective Study. Int J Anesth Res. 3(3), 96-100. doi: http://dx.doi.org/10.19070/2332-2780-1500025

Copyright: S.Gupta ${ }^{\odot}$ 2015. This is an open-access article distributed under the terms of the Creative Commons Attribution License, which permits unrestricted use, distribution and reproduction in any medium, provided the original author and source are credited.

\section{Introduction}

LC is the technique of choice for removal of gallbladder with benign pathology. Rapid improvements in surgical and anaesthetic techniques coupled with advancements in instrumentation and optics has now made LC a standard day case procedure [1]. British Association of Day Surgery (BADS) believes a day case rate of $60 \%$ is achievable for LC by most hospitals [2]. Despite the advances, considerable variation still remains across various centres in United Kingdom. National average DCLC rate for England was reported to be $16 \%$ in a recent study [3].

Many clinical concerns remain unaddressed preventing a more widespread adoption of DCLC. Of these, post-operative pain and nausea remains a challenging issue, limiting the success of same day discharge.

TAP block, first described in 2001 [4] is an effective adjunct to post-operative analgesia especially following lower abdominal incisions [5]. The technique has been used previously to provide analgesia following DCLC with mixed results [6-9]. Reduced pain could potentially translate into low opiate requirements and hence reduced sedation and opiate induced nausea and vomiting.

\section{Materials and Methods}

\section{Participants and Inclusion Criteria}

All patients deemed suitable for DCLC in an established day surgery unit at the author's institution were enrolled in the study. For 
the purpose of study DCLC was defined as admission and discharge between $8 \mathrm{am}$ and $8 \mathrm{pm}$. Patients were deemed suitable for day surgery if they met the day surgery criteria as outlined by the BADS [2]. These included patients with ASA I, II and III (stable) with good social support. Age and BMI alone were not considered as an exclusion criterion provided patients were stable with reasonable exercise tolerance. Patients were counselled for the procedure and same day discharge (before $8 \mathrm{pm}$ ) both in the clinic and during consenting. Informed consent was obtained regarding the surgical procedure and post-operative analgesia. All patients came mentally prepared for same day discharge. Ethics approval for the study was obtained from the hospital ethics committee.

\section{TAP block}

Patients were randomised (in blocks of 5) to receive a TAP block (intervention group) or No TAP block (control group) along with LC. The TAP block was administered bilaterally by a single consultant anaesthetist using landmark-based 'double pop' technique. A total of $20 \mathrm{ml}$ of $0.25 \%$ bupivacaine was used on each side. All patients also received $20 \mathrm{ml}$ of $0.25 \%$ bupivacaine infiltration at the laparoscopic port sites prior to port insertion. The patients and the day surgery recovery staff were blinded to the intervention and the control groups.

\section{Operative Technique}

Standard anaesthetic techniques were used along with a laryngeal mask airway (LMA). At induction patients received 5-10 mgs of titrated morphine along with $100 \mathrm{mcg}$ of Fentanyl and Ondansetron. Nasogastric tubes were avoided and antibiotics were only used if biliary spill was encountered during the procedure. All operations were conducted by the same team of two surgeons on a morning day surgery list, using standard 3 port open Hason access $(1 \times 10 \mathrm{~mm}$ and $2 \times 5 \mathrm{~mm}$ ports). A low pressure pneumo-peritoneum using 10-12 $\mathrm{mmHg}$ of carbon dioxide was used throughout the study.

\section{Post-operative Care}

Standardised post-operative analgesia and anti-emetics were prescribed to all patients. These included Acetaminophen $1 \mathrm{~g} / 6 \mathrm{~h}$, Codeine 60mg/6h and Ondansetron 4mg/8h. Diclofenac and Morphine was used for break through pain. Early mobilisation by a dedicated nursing team in the recovery was the corner stone of post-operative care. All patients were planned to be discharged from the day surgery recovery unit before $8 \mathrm{pm}$.

\section{Outcome Measures}

The primary outcome measure for the study was comparison of post-operative pain with and without TAP block as part of a balanced anaesthetic regimen. Secondary outcome measures included post-operative nausea/vomiting scores, sedation scores, length of post-operative hospital stay, complication rates, re-admission rates and overall patient satisfaction scores.

Post-operative data was collected prospectively by recovery nurses using a structured proforma. Pain, nausea and sedation were scored and recorded in recovery at $2 \mathrm{~h}, 4 \mathrm{~h}$, time of discharge and $24 \mathrm{~h}$ post-operatively. Patients rated their pain on a 10 point oral response scale, whilst post-operative nausea, vomiting (PONV) and sedation were scored using a three point scale (0-3). Since all patients were operated as day cases, $24 \mathrm{~h}$ scores were recorded telephonically which also served as a safety net ensuring expected recovery at home. Student's t test was used to calculate any statistical significance between the two groups.

\section{Results}

\section{Patient demographics (Table I)}

A total of 53 patients underwent DCLC for symptomatic gall stone disease under the care of a single surgical team between May 2011 and April 2013. Of these 26 were in the TAP group and 27 in the No TAP group. Overall sex ratio was 13 males to 40 females (1:3) with an average age of 47.7 years (range 18-81 years). A total of 33 patients were ASA I, 16 patients were ASA II and one patient was ASA III (stable). Other vital parameters for the group as a whole included an average body weight of $76.1 \mathrm{~kg}$ (range $54.2-101 \mathrm{~kg}$ ) with a mean BMI of 27.8 (range 19-40). The mean operative time for the LC was 41.7 minutes (range 20-120 minutes). The demographic details for both the groups (TAP and NO TAP) are shown in Table I. As evident, both the groups were well matched with no statistically significant difference in any of the demographic parameters.

\section{Post-operative pain scores (Table II)}

The pain scores for the group as a whole (on a VAS of $0-10$ ) was recorded as 3.8 (range $0-8$ ) at $2 \mathrm{~h}$ post-operatively which reduced to 2.10 (range 0-7) on discharge and 2.67 (range $0-7$ ) at $24 \mathrm{~h}$ respectively. The post-operative pain scores for both the groups (TAP and No TAP) are shown in Table II. The results did not

Table 1. Patient demographics.

\begin{tabular}{|c|c|c|c|c|}
\hline & Overall & TAP $(\mathbf{n = 2 6 )}$ & No TAP $(\mathbf{n = 2 7 )}$ & P values \\
\hline Male: Female & $13: 40$ & $6: 20$ & $7: 20$ & 0.810 \\
\hline Mean Age (years) & $47.7(18-81)$ & $47.7(18-81)$ & $47.7(19-79)$ & 0.993 \\
\hline Number of cases & 53 & 26 & 27 & \\
\hline Mean Op. time (mins) & $41.7(20-120)$ & $43.2(20-75)$ & $40.2(20-120)$ & 0.53 \\
\hline ASA I & 33 & 15 & 18 & \\
\hline ASA II & 16 & 9 & 7 & 0.486 \\
\hline ASA III & 1 & 0 & 1 & \\
\hline Mean Weight (Kg) & $76.1(54.2-101)$ & $74.8(54.2-90.5)$ & $77(56-101)$ & 0.578 \\
\hline Mean BMI & $27.8(19-40)$ & $27(21-37)$ & $28.4(19-40)$ & 0.345 \\
\hline
\end{tabular}


show any statistically significant difference in the pain scores for the two groups. Interestingly the pain scores were consistently higher the following morning than at discharge, perhaps indicating wearing off of the local anaesthetic effect at port sites which was common to both the groups.

\section{Post-operative nausea and sedation scores (Table III)}

The post-operative nausea and sedation scores were extremely low with no meaningful differences between the two groups.

\section{Post-operative clinical outcomes (Table IV)}

Mean post-operative stay for the group as a whole was $6.12 \mathrm{~h}$ (range of 4-22 hrs). This varied between 5.86h (4-8h) for the TAP group and $6.38 \mathrm{~h}(5-22 \mathrm{~h})$ for the No TAP group respectively (Table IV). Statistically this difference was not significant $(\mathrm{p}=0.482)$. One patient in the No TAP group was converted to open due to bleeding. Overall three patients had delayed discharge (after $8 \mathrm{pm}$ ):
TAP group - 2 (urinary retention-1, unexplained hypotension-1) and No TAP group - 1 (social reasons). Overall combined complication rate for both the groups was $11 \%$ (6 out of 53). These included: TAP group-3 (retention urine-2, unexplained hypotension-1), No TAP group-3 (conversion to open for bleeding-1, umbilical port site infection-2). There was no statistical difference in the complication rates between the two groups. No patient required re-admission following discharge from the hospital.

\section{Patient Satisfaction Scores}

High patient satisfaction scores were reported for both the groups. Overall 42 patients described this as very satisfied (21 in each group), 9 patients as satisfied (TAP-5, No TAP-4) and one patient as neutral (No TAP group). One patient in the No TAP group was un-satisfied with the overall care. These scores were statistically not significant.

\section{Discussion}

Table 2. Post-operative pain scores.

\begin{tabular}{|c|c|c|c|c|}
\hline Time post operation & Overall pain score (range) & TAP (range) & No TAP (range) & P values \\
\hline $\mathbf{2 h}$ & $3.81(0-8)$ & $3.65(0-8)$ & $3.95(0-8)$ & 0.683 \\
\hline $\mathbf{4 h}$ & $2.69(0-7)$ & $2.38(0-6)$ & $3.0(0-7)$ & 0.339 \\
\hline Discharge & $2.10(0-7)$ & $1.96(0-6)$ & $2.24(0-7)$ & 0.539 \\
\hline Post-op Day 1 & $2.67(0-7)$ & $2.88(0-6)$ & $2.44(0-6)$ & 0.491 \\
\hline
\end{tabular}

Pain measured on a 10 point oral response scale $(0=$ no pain, $10=$ severe pain $)$

Table 3. Post-operative nausea and sedation scores.

\begin{tabular}{|c|c|c|c|c|}
\hline Nausea & Overall score (range) & TAP & No TAP & P values \\
\hline 2h & $0.65(0-3)$ & $0.54(0-3)$ & $0.77(0-2)$ & 0.177 \\
\hline $4 \mathrm{~h}$ & $0.29(0-2)$ & $0.27(0-2)$ & $0.31(0-2)$ & 1.000 \\
\hline Discharge & $0.16(0-1)$ & $0.12(0-1)$ & $0.20(0-1)$ & 0.465 \\
\hline Post-op day 1 & $0.19(0-3)$ & $0.15(0-3)$ & $0.23(0-2)$ & 0.404 \\
\hline \multicolumn{5}{|c|}{ Sedation } \\
\hline 2h & $0.92(0-3)$ & $0.92(0-3)$ & $0.92(0-2)$ & 1.000 \\
\hline 4h & $0.46(0-2)$ & $0.46(0-2)$ & $0.46(0-2)$ & 0.953 \\
\hline Discharge & $0.16(0-3)$ & $0.12(0-1)$ & $0.20(0-3)$ & 0.834 \\
\hline Post-op day 1 & $0.15(0-2)$ & $0.15(0-2)$ & $0.15(0-2)$ & 1.000 \\
\hline
\end{tabular}

Post-op nausea and vomiting $(0=$ none, $1=$ mild, $2=$ moderate, $3=$ severe $)$

Sedation $(0=$ awake and alert, $1=$ quietly awake, $2=$ asleep but arousable, $3=$ deep sleep $)$

Table 4. Hospital Stay, complications and re-admissions.

\begin{tabular}{|c|c|c|c|c|}
\hline & Overall & TAP (n=26) & No TAP (n=27) & P value \\
\hline Mean post-op stay (h) & $6.12(4-22)$ & $5.86(4-8)$ & $6.38(5-22)$ & 0.482 \\
\hline Complications & $\mathbf{6 ~ ( 1 1 \% )}$ & $\mathbf{3}$ & $\mathbf{3}$ & \\
\hline Conversion to open & 1 & 0 & 1 & \\
\hline Unexplained hypotension & 1 & 1 & 0 & \\
\hline Urinary retention & 2 & 2 & 0 & \\
\hline Port site infection & 2 & 0 & 2 & \\
\hline Delayed discharge & 3 & 2 & 1 & \\
\hline Readmissions & $\mathbf{0}$ & $\mathbf{0}$ & $\mathbf{0}$ & \\
\hline
\end{tabular}


Ever since its first description in 2001, TAP block has been used increasingly to relieve pain associated with anterior abdominal wall incisions. A recent review [5] and meta-analysis [10] has reported the technique to be an effective adjunct to multi modal post-operative analgesia following a range of abdominal surgical procedures.

The TAP block technique has evolved immensely since its original description of landmark-based 'double pop' approach [4] to an ultra-sound guided TAP block [11] and recently laparoscopic guided TAP block [12]. More recently the technique has been further modified to combine the benefits of ultra-sound and laparoscopic guidance [13]. These measures are likely to improve the accuracy of the drug delivery into the neuro-vascular plane (TAP) and hence its effectiveness.

Efficacy of TAP block in relieving post-operative pain following lower abdominal procedures such as gynaecological procedures including caesarean section, colo-rectal surgery, abdominoplasty and open appendecectomy is now well established [5, 10, 14] However its analgesic role in upper abdominal procedures including LC remains debatable [15]. The present study failed to show any significant improvement in terms of post-operative pain, nausea, sedation or overall hospital stay following DCLC with TAP block.

Current review of literature reveals 4 published trials assessing the role of TAP block with LC. The first RCT [7] (Randomised controlled trial) was reported in 2009 and included 42 patients randomised into TAP and No TAP block groups. The study revealed significant reduction in intra-operative Sufentanil requirements $(p<0.01)$ along with reduced use of morphine post-operatively in the recovery room $(\mathrm{p}<0.05)$ and at $24 \mathrm{~h}(\mathrm{p}<0.05)$. PCA (patient controlled analgesia) was used routinely for post-operative pain relief which is rather unusual and pain scores were not assessed in the study. Interestingly all the laparoscopic port sites were sub-umbilical which would be rather un-conventional and perhaps could enhance the benefit of TAP block in the intervention group.

Another RCT [8] from 2010 reported 54 patients randomised into three groups. These included two groups with TAP block with $0.25 \%$ and $0.5 \%$ bupivacaine respectively along with a control arm with No TAP block. Study failed to show any significant difference between the two intervention groups receiving the TAP block $(0.25 \%$ Vs $0.5 \%$ bupivacaine). Statistically significant reduction in ketorolac $(\mathrm{p}<0.001)$ and fentanyl $(\mathrm{p}<0.05)$ usage was noted with TAP groups when compared to no TAP group. Pain scores were also reduced in the TAP groups over $24 \mathrm{~h}$ period $(<0.001)$.

Ortiz in 2012 [9] prospectively randomised 74 patients into ultrasound guided TAP block versus local infiltration of port sites with bupivacaine alone. The study failed to show any significant difference in pain scores at $4 \mathrm{~h}(\mathrm{p}-0.18)$ and $24 \mathrm{~h}(\mathrm{p}-0.23)$ postoperatively. Incidence of nausea at $24 \mathrm{~h}$ was also not different between the two groups at $24 \mathrm{~h}(\mathrm{p}-0.64)$.

Peterson in 2012 [6] also prospectively randomised 74 patients undergoing LC into TAP and No TAP (placebo) groups in a double blind controlled fashion. The $24 \mathrm{~h}$ pain scores at rest did not show any significant difference between the two groups although this did reach to significance on coughing $(p=0.04)$. Total mor- phine requirements remained low in both the groups and hence any difference is of little clinical relevance. No differences in the sedation, nausea or vomiting scores were noted.

The current study failed to show any significant benefit from TAP block which could be multi-factorial. Firstly there may be genuinely no significant analgesic benefit from TAP block in LC as evidenced by the last two trials $[6,9]$. Or perhaps the addition of port site local anaesthetic infiltration took away the little analgesic benefit offered by TAP block. This fact is amply supported by Ortiz's study [9]. The TAP space contains inter-costal nerves from T7-T12 and L1. Whereas the lower inter-costal nerves are blocked effectively, the same may not be as true for higher intercostal nerves [16]. It is therefore possible that the upper abdominal ports used in various upper abdominal procedures including LC may not be blocked effectively. This could perhaps be the main reason for a lack of its analgesic effect in our and other studies.

A higher level of analgesic block has been reported by injection of local anaesthetic into sub-costal TAP. A RCT by Tolchard et al [17] revealed improved pain scores with significantly reduced fentanyl and morphine usage and reduced hospital stay in patients with sub-costal TAP block when compared with conventional port site infiltration for LC. Lastly our study was based on landmark-based 'double pop' technique which perhaps may not be as accurate in delivering the drug in the correct plane [18]. Interestingly the only ultra-sound guided TAP block trial reported has also failed to show any analgesic benefit [9].

In conclusion, based on the current study the TAP block does not seem to offer any additional analgesic benefit in patients undergoing LC. Some of the available evidence however does suggests some analgesic benefit from TAP block when compared to no TAP control group. This advantage of TAP block seems to disappear when compared to port site local anaesthetic infiltration alone. The role of sub-costal block appears promising and any future trials must include the same.

\section{Acknowledgement}

The authors would like to acknowledge the day surgery recovery nurses for their meticulous assessment and recording of various post-operative scores.

\section{Disclosure}

Mr Sanjay Gupta, Mr Shobhit Arya, Mr Faisal El Medani and Dr Tim Walker have no conflict of interest or financial ties to disclose.

\section{References}

[1]. Audit Commission (2001) Day surgery: review of national findings. London: Audit Comission Publications.

[2]. (2009) British Association of Day Surgery (3rd Edtn), BADS Directory of Procedures London.

[3]. (2009) Department of Health. Hospital Episode Statistics www.hesonline. nhs.uk

[4]. Rafi AN (2001) Abdominal field block: a new approach via the lumbar triangle. Anaesthesia 56: 1024-1026.

[5]. Findlay JM, Ashraf AQ, Congahan P (2012) Transversus abdominis plane (TAP) blocks - A review. The Surgeon 10: 3611-3667.

[6]. Peterson PL, Stjernholm P, Kristiansen VB, Torup H, Hansen EG, et al. (2012) The beneficial effect of transversus abdominis plane block after lapa- 
roscopic cholecystectomy in day-case surgery - a randomised clinical trial. AnesthAnalg 115: 527-533

[7]. El-Dawlatly AA, Turkistani A, Kettner SC, Machata AM, DelviMB, et al. (2009) Ultrasound-guided transverse abdominis plane block: description of a technique and comparison with conventional systemic analgesia during laparoscopic cholecystectomy. Br J Anaesth 102: 763-767.

[8]. Ra YS, Kim CH, Lee GY, Han JL (2010) The analgesic effect of the ultrasound-guided transverse abdominis plane block after laparoscopic cholecystectomy. Kor J Anesthesiol 58: 362-368.

[9]. Ortiz J, Suliburk JW, Wu K, Bailard NS, Mason C, et al. (2012) Bilateral transversus abdominis plane block does not decrease post-operative pain after laparoscopic cholecystectomy when compared with local anesthetic infiltration of trocar insertion sites. RegAnesth pain Med 37: 188-192.

[10]. Johns N, O’Neill S, Ventham NT, Barron F, Brady RR, et al. (2012) Clinical effectiveness of transversus abdominis plane (TAP) block in abdominal surgery: a systematic review and meta-analysis. Colorectal Disease: The Official Journal of the Association of Coloproctology of Great Britain and Ireland 14: e635-642.

[11]. Hebbard P, Fujiwara Y, Shibata Y, Royse C (2007) Ultra-sound guided transversus abdominis plane (TAP) block. Anaesthesia and intensive care 35: 616617.

[12]. ChetwoodA, Agarwal S, Hrouda D, Doyle P (2011) Laparoscopic assisted transversus abdominis plane block: a novel insertion technique during lapa- roscopic nephrectomy. Anaesthesia 66(4): 317-318.

[13]. Gupta S, El Medani F, Jain K (2014) Laparoscopic guided transversus abdominis plane (TAP) block - a modified technique. Int J Anesth Res 2(7): $1-2$.

[14]. Keller D, Ermlich BO, Delaney CP (2014) Demonstrating the benefits of transversus abdominis plane block on patient outcomes in laparoscopic colorectal surgery: review of 200 consecutive cases. J Am CollSurg219(6): 1143-1148.

[15]. Keir A, Rhodes L, Kayal A and Khan OA (2013) Doestransversus abdominis plane (TAP) local anaesthetic block improve pain control in patients undergoing laparoscopic cholecystectomy? A best evidence topic. Int J Surg 11(9):792-4.

[16]. Shibata Y, Sato Y, Komatsu T (2007) Transversus abdominis plane block. Anesthesia and Analgesia 105: 883.

[17]. Tolchard S, Davies R, Martindale S (2012) Efficacy of sub-costal transversus abdominis plane block in laparoscopic cholecystectomy: comparison with conventional port-site infiltration. J AnaesClin Pharm 28: 339-343.

[18]. McDermott G, Korba E, Mata U, Jagirdar M, Naryanan N, et al. (2012) Should we stop doing blind transversus abdominis plane blocks? 108(3): 499-502. 